\title{
Research on the Functions of Teaching Secretary in Colleges and Universities in the Context of Application-oriented Technical Transformation
}

\author{
Song Yuqin \\ Xi'an Peihua University, Xi'an, China
}

\begin{abstract}
Keywords: application-oriented technical transformation; teaching secretary; function; quality
\end{abstract}
\begin{abstract}
Application-oriented technical transformation promotes the reform and development of undergraduate higher education by Ministry of Education, according to the national strategy of educational development. Due to the unique characteristics of application-oriented technical undergraduate colleges and universities, there is great difference in cultivation objective, cultivation requirements, teaching methods, practical teaching and specialty setting from regular colleges and universities. Teaching secretary, as the assistant of teaching and management of school and secondary school (department) leaders, is one of main force of educational teaching and management staff and the grassroots executor of comprehensive deepening of educational overall reform, playing an important role in improving the teaching quality. This paper discusses the functions of teaching secretary in colleges and universities in the context of application-oriented technical transformation.
\end{abstract}

\section{Introduction}

With the continuous development of social economy in China, the requirements for the talents in different levels from the society is stronger and stronger. In The Deepening of Modern Vocational Education Development by the State Council, colleges and universities who develop undergraduate applied vocational education are called "application-oriented technical higher institutions", referred as "applied colleges and universities". Applied colleges and universities position themselves "to be based on local area, rooted in industry, focus on application in cultivation objective, pay attention to operational capability, and stress the practicalness of training process, to train high-level technical applied talents for local economy and society to adapt to the front-line requirements of production, construction, management and service”. Different from research-oriented or academic colleges and universities, applied colleges and universities have their own characteristics in talent training objective, curriculum system, specialty setting, teaching staff construction, teaching method and training level, in the process of implementing education. [1] In recent years, local regular undergraduate colleges and universities conduct the educational teaching transformation, in the level of talent cultivation, improve the system of talent cultivation and effectively connect to higher vocational education, extending from academy education to undergraduate education. Applied talent cultivation becomes the product of higher education transforming from elite education to mass education, and applied undergraduate education also appears as a new educational type. [2]

Teaching management is the core work of higher institutions, and important work of higher institution management. The major task and content is to organize teaching activities, coordinate and optimize the benign cycle of teaching and learning, effectively solve the contradictions between teaching and learning, guarantee the comprehensive realization of teaching objective and improve the teaching quality. [3] The transformation from regular to applied colleges and universities, is faced with great change of teaching concept. The transformation of undergraduate colleges and universities in teaching management is still in exploratory stage, which needs to be perfected further to improve the effectiveness of teaching management in applied undergraduate colleges and universities.

Teaching secretary, as the grassroots executor of teaching management, plays a vital role in teaching, and is the indispensable part of teaching management system and basis of guaranteeing the operation of various teaching work. Teaching secretary shall reasonably arrange teaching 
activities in a certain teaching organization form according to defined teaching objective in standardized training scheme and standard course plan, to guarantee the successful implementation of teaching activities. At the same time, in actual teaching service, teaching secretary is required to connect all relative teaching positions together, playing a coordinating and cooperating role. [4]

\section{The Functions of Teaching Secretary in Colleges and Universities}

\subsection{The function of service and communication}

Teaching secretary is the center of teaching management, playing an important role in communication. Communication is penetrated throughout each aspect of teaching management. If the function can be played well, the work will be effectively implemented. According to the requirements of school and opinions of secondary school (department) leaders, teaching secretary shall think, plan, arrange and deal with problems, coordinate the relation of various aspects, unify the ideology and reach a consensus. It is more important to assistant leaders to make work arrangement, make decisions scientifically and implement work to make sure the clear work procedures. Besides, teaching secretary is required to make contact with the office of academic affairs, school (department) leaders, teachers and students. The function of service is mainly manifested in the regular implementation of teaching activities, the regular maintenance of teaching order and the timely accomplishment of teaching tasks, which is obvious.

\subsection{The function of adviser and assistance}

In addition to serving and communicating the personal connection of each department inside the school, teaching secretary also shall assistant the office of academic affairs and school (department) leaders to study and stipulate teaching system and schemes and so on, and provide opinions and suggestions on information for reference, organize and coordinate the stipulation of teaching documents, with the aid of practical experience from the participation of specific teaching affairs in daily teaching. When implementing teaching documents, teaching secretary shall collect and summarize teaching information in the implementation, find out and solve timely problems, and provide decision support for the revision and correction of teaching documents, so as to perform the function of adviser and assistance to improve the teaching quality.

\subsection{The function of coordination and organization}

As for the actual specific affairs of teaching management, school leaders, the director of academic affair office and leaders of schools (department) in charge of teaching, are mainly responsible for the overall work of school, academic affair and schools (department), and plan comprehensive teaching management. Whereas, in specific teaching affairs, teaching secretary is required to deliver teaching information, implement teaching tasks and plan teaching management, shouldering complex function of coordination and organization. For instance, teaching secretary performs the function of coordination and organization in making teaching schedule, textbooks subscription and distribution, implantation of teaching plan, exam organization, evaluation management of marks, assessment of teacher's workload and teaching payment, and evaluation and management of students' diploma and certification of degree.

\subsection{The function of information management}

A large quantity of text, videos, images and objects have been accumulated in teaching management over years, therefore, teaching secretary is required to collect, arrange, file and save these materials to judge whether those are in accordance with teaching standard or not, such as teaching plan, teaching program, teaching presentation, teaching reform and teaching process management. At the end of each semester, teaching secretary shall collect, arrange, file and save those materials according to the requirement of archives management, which is valuable for the stable teaching order and deepening teaching reform. 


\section{The New Transformation of Teaching Management in Applied Colleges and Universities}

Outline of National Medium and Long-term Educational Reform and Development Plan (2010-2020), (hereinafter referred as "Outline"), pointed out that "to focus on the capacity, optimize knowledge structure, enrich social practice, and strengthen capacity cultivation”, [5], which is the new requirements for the talent cultivation of applied undergraduate colleges and universities. According to the requirements, applied colleges and universities adhere to the "capacity-oriented" talent training policy, intensify the capacity training of students, formulate a series of standards for the teaching, including talent training scheme, teaching program, classroom teaching, experimental teaching, practical internship teaching, exam, curriculum design, graduation thesis (design) and so on.

A school is centered on teaching, and teaching management shall serve the teaching in operation mechanism of teaching management. Due to the great changes in teaching standard, school, the office of academic affairs, schools (department) shall implement new standard, and specific positions in teaching management, such as the president, the director of academic affairs office, school (department) leaders and teaching secretary shall be connected to teaching management, transforming old-fashioned concept and ideology and work methods, so as to perform well the teaching management in applied colleges and universities.

\section{Suggestions for Teaching Secretary in Applied Colleges and Universities in the Context of Transformation}

\subsection{To transform ideological concept to perform the work successfully}

In the background of application-oriented technical transformation, the work of teaching secretary is still in complex and trivial state with great pressure, so the positioning and transformation of teaching management is a key step to realize the transformation. The teaching secretary of undergraduate colleges and universities shall actively adjust their mind, adapt changes of new teaching trend, abandon backward and outdated work concept, based on students' development, and change the ideology of manager of students to the server of students. Teaching, teacher and student are three beacons in the work of teaching secretary and the basis of contact between teaching secretary and students. Besides, in order to practically implement all work, it is necessary for teaching secretary to report and communicate the work implementation regularly to make sure the successful operation of all work, and fine, accurate and in-place management work, without ambiguous and vacuum zone.

\subsection{To enhance the consciousness of innovation to become one of decision-makers}

With the deepening of transformation, corresponding reform shall also be conducted on teaching system of colleges and universities, which puts forward new problems for the role of teaching secretary. In the old teaching management mode, teaching secretary purely served for decision-makers of teaching management, which is not suitable anymore. However, teachings secretary shall become a better adviser, rather than an assistant. For instance, when school (department) leaders encounter teaching problems, teaching secretary is required to actively express opinions, without being limited by traditional management system, put forward suggestions on teaching practice, with unique opinions and viewpoints, and dare to put forward suggestions and opinions for decision-makers of teaching management, showing the consciousness and capability of innovation in the operation of regular teaching activities and corresponding suggestions, so as to promote the implementation of decisions. Teachers and students in colleges and universities are all intellectuals with advanced ideology. Compared to teachers, the ideology of students are more advanced to that of teachers, more adapting to the times. Whereas, the comprehensive competence and innovative consciousness of teaching secretary as a server is more important. Therefore, in order to enhance the capacity of solving problems, teaching secretary shall fully strengthen the consciousness of innovation and apply it to daily communication. 


\subsection{To co-build transformation platform to share information service}

In the context of transformation and development, various kinds of teaching information shall be collected and summarized repeatedly. For school, teaching managers and students, information held by them are not equivalent, which will influence the efficiency of teaching management. Therefore, first of all, it is necessary to adopt informationalized management mode, based on strong Internet infrastructure, and build an information service platform with high shareability, so that information of teachers, students, curriculum, and teaching can be informationalized to improve the timeliness and accuracy of teaching service. Secondly, modern communication platforms, such as campus network, teaching information network, school website, online QQ, and WeChat platform can be fully utilized, to open new educational concept, new trends of discipline, new teaching methods, new changes of schools to the public, so as to provide reference materials and news for relative departments, teachers and students, so that they can be actively involved in teaching activities to promote the benign development of colleges and universities.

\subsection{To cultivate comprehensive capability to adapt to the requirement of transformation}

Due to different requirements of transformation for teaching management, teaching secretary shall be equipped with professional quality, high responsibility, sense of mission and rigorous work attitude. Teaching secretary is required to reasonably arrange teaching activities, and give feedback in time on management of teaching, teaching affairs and teaching information to make sure the regular teaching. Firstly, teaching secretary must be equipped with better comprehensive quality, strengthen the consciousness of service, actively interact with teachers and students, perform the communicator between them, continuously accumulate experience and explore innovations of teaching management in practice. Secondly, teaching secretary shall have higher management capability, familiar with new document, new system and new work procedure of teaching management in applied transformation, besides, have a certain understanding of discipline and professional knowledge to effectively exert the function of coordination and service. To meet the need of applied teaching, it is necessary to participate in advanced training and communication of teaching management to enhance the level of management.

\section{Conclusion}

In the times of globalization and diversification, with the deepening transformation of undergraduate colleges and universities, it is urgent to introduce more diversified educational concept and educational methods to innovate the education. As for teaching, it is required to intensify interactional, go for the opening-up and realize the inclusiveness, so as to bring more possibilities to talent cultivation. The functions of teaching secretary are also incessantly enriched and improved with the transformation and development. Teaching secretary personnel shall be equipped with basic competence of duties and responsibilities, transformation of ideological concept, innovative work consciousness, continuous learning of skills and knowledge, to make contribution to the objective of cultivating high-quality and high-competence applied talents in colleges and universities.

\section{References}

[1] Huang Cui. Research and Practice of Undergraduate Teaching Quality Standard in Applied Colleges and Universities -Taking Hohai University Wentian College as an Example [J]. China Economist, 2017 (10): 224-225.

[2] Zhu Lianghua, Yang Xichun. Research on the Training Model of Application-Oriented Technical Talents in Local Undergraduate Colleges Universities in the Context of Transformation and Development [J]. Journal of Guangxi Teachers Education University, 2017, 32 (06): 59-63.

[3] Qiu Xuemei, Zhang Ya. Research on Teaching Management Mode and Path of the Transformation and Development from Newly-built Undergraduate Colleges and Universities to 
Applied Undergraduate Education [J]. China Economist, 2016 (04): 214-216.

[4] Liang Huan. The Role and Quality Requirement of Teaching Secretary in Teaching Management in Colleges and Universities [J]. MING (Attitude), 2018 (11): 202+229.

[5] Excerpt of Outline of National Medium and Long-term Educational Reform and Development Plan (2010-2020) [J]. Education Science Forum, 2017 (20): 3. 